\title{
Testing four hypotheses to explain partial migration: balancing reproductive benefits with limits to fasting endurance
}

\author{
Carl G. Lundblad ${ }^{1,2} \cdot$ Courtney J. Conway ${ }^{3}$ (D) \\ Received: 30 August 2019 / Revised: 19 December 2019 / Accepted: 20 December 2019 / Published online: 27 January 2020 \\ (C) This is a U.S. government work and not under copyright protection in the U.S.; foreign copyright protection may apply 2020
}

\begin{abstract}
Seasonal migration is ubiquitous in animals, and yet its underlying cause(s) remain poorly known. Species exhibiting shortdistance altitudinal migration and intraspecific variation in migratory behavior (partial or differential migration) are ideal study systems for examining the selective pressures that affect individual migratory decisions. We used an individually marked population of yellow-eyed juncos, breeding along a 1000-m elevational gradient and migrating up and down that gradient, to examine the morphological, behavioral, and reproductive traits associated with migratory behavior. We tested the four most wellknown hypotheses proposed to explain partial migration: the thermal tolerance, fasting endurance, dominance, and arrival time hypotheses. Our results indicate that: (1) limits to juncos' fasting endurance constrain their ability to overwinter at high elevations, in support of the fasting endurance hypothesis, (2) differences in body size mediate fasting ability and are associated with variation in migratory behavior and overwinter apparent survival, (3) migratory behavior interacts with reproductive success, in partial support of the arrival time hypothesis, and (4) additional mechanisms that are not captured by the four well-known hypotheses might better explain individual variation in migratory behavior. Less migratory females achieved greater nesting success the following breeding season. Among males, nesting success influenced migratory tendency the following winter. Successful males may either migrate to a more benign winter climate without paying reproductive costs, or high levels of parental effort might physiologically constrain their ability to overwinter in harsh climates.
\end{abstract}

\section{Significance statement}

Migration is a costly behavior, so migration must yield fitness benefits, at least for some individuals. Species in which migratory behavior varies among individuals in the same population provide an under-utilized opportunity to understand the costs and benefits that mediate individual migratory decisions. By marking and tracking a population of yellow-eyed juncos, we found that larger individuals were less likely to migrate, and this held true even within a sex class (males). Smaller individuals were not only more likely to migrate but also had lower apparent survival, and these differences were driven by size-related differences in fasting ability. Less migratory females accrued reproductive benefits, but males with the highest reproductive success were not less likely to migrate as predicted by the arrival time hypothesis. Our study demonstrates that migratory decisions balance the potential reproductive benefits and survival risks of overwintering on high-elevation breeding grounds.

Keywords Altitudinal migration · Arrival time hypothesis · Body size hypothesis · Carry-over effects $\cdot$ Junco phaeonotus . Yellow-eyed junco

Communicated by W. Wiltschko

Carl G. Lundblad

carl.lundblad@gmail.com

Courtney J. Conway

cconway@uidaho.edu

1 Arizona Cooperative Fish and Wildlife Research Unit, School of Natural Resources and the Environment, 104 Biological Sciences East Building, University of Arizona, Tucson, AZ 85721, USA
2 Present address: Idaho Cooperative Fish and Wildlife Research Unit, 875 Perimeter Drive MS 1141, University of Idaho, Moscow, ID 83843, USA

3 U.S. Geological Survey, Idaho Cooperative Fish and Wildlife Research Unit, 875 Perimeter Drive MS 1141, University of Idaho, Moscow, ID 83844, USA 


\section{Introduction}

Animal migration is among the most fascinating and yet poorly-understood of animal behaviors. Despite a century of research on migratory behavior, the ultimate cause of migration remains a topic of debate (Greenberg and Marra 2005; Boyle and Conway 2007; Somveille et al. 2015; Winger et al. 2018). Because migration is an inherently seasonal phenomenon, elucidating its proximate and ultimate causes will help us anticipate and mitigate the effects of climate change on migratory animals. Migration comes with obvious costs including the risks associated with exposure to uncertain foraging conditions, unfamiliar predator communities, uncertain or lost access to former breeding territories, and the direct energetic costs of long-distance movements (Sillett and Holmes 2002; Wikelski et al. 2003; Newton 2008; Strandberg et al. 2010; Klaassen et al. 2014). Therefore, migration must yield substantial benefits that outweigh those costs, at least in some individuals. Indeed, many species exhibit intraspecific variation in migratory behavior (Lack 1943; Ketterson and Nolan 1976; Lundberg 1988) which often reflects context-dependent choices (Ogonowski and Conway 2009). Why would some individuals in a breeding population migrate while others within the same breeding population remain sedentary during the non-breeding season? Most hypotheses proposed to explain partial migration assume that residency on the breeding grounds confers some type of reproductive benefit(s) but that year-round residency by the entire population is constrained either by seasonal resource limitation or by physiological intolerance of winter weather.

Species that migrate short distances, altitudinally, and exhibit partial migration provide powerful systems for gaining insight into the underlying cause(s) of migration. Shortdistance altitudinal migration is more common than previously recognized (Boyle 2011, 2017; Barçante et al. 2017). Studies of short-distance migrants may be more tractable than those of long-distance migrants because it is easier to track individuals throughout their migratory cycle and they facilitate the direct observation of the selective pressures that drive migratory movements. Recent evidence suggests that partial migration may also be more common than obligate migration (Berthold 2001; Boyle 2017), and partial migration is often assumed to be an intermediate evolutionary step between sedentary and obligate migratory behaviors (Gauthreaux 1982; Terrill 1991; Berthold 1996). Therefore, understanding the selective pressures and trade-offs that mediate different migratory decisions within populations can lend insights into the evolution of migratory behavior more generally (Berthold 1999). However, studies of partial migration were uncommon until recently (see Lundberg 1985; Belthoff and Gauthreaux 1991b; Catry et al. 2004; Boyle 2008; Jahn et al. 2010; Fudickar et al. 2013; Hegemann et al. 2015, 2019 and references therein).
Numerous hypotheses have been proposed to explain why migratory behavior varies among individuals in a single population. Partial migration may result from a genetically predetermined dimorphism (Lack 1943; Biebach 1983). Previous studies, however, have shown that individual migratory strategies are often plastic rather than genetically fixed (Schwabl 1983; Ogonowski and Conway 2009), as we would expect in a system characterized by facultative migration (Ketterson and Nolan 1976; Newton 2012). Five wellknown condition-dependent hypotheses assume that variation in migratory phenotypes results from facultative decisions based on interactions between intrinsic factors including age, sex, social status, and body condition, and extrinsic factors such as weather and food availability (Ketterson and Nolan 1976; Cristol et al. 1999; Chapman et al. 2011; Table 1). Many previous studies of partial migration have tested only predictions regarding the geographic distribution of demographic classes (age and sex) during the winter (e.g., Morton 1984; Shepherd et al. 2001; Catry et al. 2004; Nebel 2006; Guillemain et al. 2009; Bosman et al. 2012). At least three major challenges limit the ability to interpret such results:

(1) all five condition-dependent hypotheses often make similar predictions regarding how migratory behavior should differ among sex and age classes (Morton 1984; Boyle 2008). For example, males are often larger than females, socially dominant over females, and are usually the sex which establishes breeding territories. Therefore, all five condition-dependent hypotheses predict that female birds will be more migratory than males (and they typically are; Ketterson and Nolan 1976; Prescott 1990; Cristol et al. 1999; Guillemain et al. 2009; Fudickar et al. 2013).

(2) predictions based on differences in migratory tendency of age and sex classes fail to directly test the mechanistic basis of each hypothesis. That is, predictions that validate the actual mechanisms and assumptions underlying each hypothesis are rarely tested.

(3) testing predictions based on seasonal assortment of sex and age classes invokes circular reasoning. The condition-dependent hypotheses were inspired by the observation that, in many species, females migrate greater distances than males (Ketterson and Nolan 1976). Little progress is made by testing purported predictions of a hypothesis which we already know are true and are the very patterns that the hypothesis was proposed to explain.

A better understanding of the causes of partial migration requires studies which simultaneously test novel predictions regarding the explicit mechanisms underlying each of those hypotheses. Although the hypotheses are 
Table 1 Five condition-dependent hypotheses proposed to explain intraspecific variation in migratory tendency (i.e., partial and differential migration) and a new hypothesis that we propose based on our results

\begin{tabular}{|c|c|c|}
\hline Hypothesis & Description & Citations \\
\hline $\begin{array}{l}\text { Thermal tolerance (body } \\
\text { size) }\end{array}$ & $\begin{array}{l}\text { Because body volume (and therefore metabolic heat production) increases with overall } \\
\text { body size more quickly than surface area (across which heat is lost), larger } \\
\text { individuals are better able to thermoregulate and avoid hypothermia, compared to } \\
\text { smaller individuals. Hence, smaller individuals are more likely to migrate away from } \\
\text { their breeding area during winter. }\end{array}$ & $\begin{array}{l}\text { Kendeigh 1945; Ketterson and } \\
\quad \text { Nolan } 1976\end{array}$ \\
\hline $\begin{array}{l}\text { Fasting endurance (body } \\
\text { size) }\end{array}$ & $\begin{array}{l}\text { Because the capacity to store energy as fat increases with body size more quickly than } \\
\text { does metabolic rate, larger individuals can endure longer periods of fasting during } \\
\text { periods of food limitation. Hence, smaller individuals are more likely to migrate } \\
\text { away from their breeding site during the season with lowest food abundance. }\end{array}$ & $\begin{array}{l}\text { Calder 1974; Ketterson and Nolan } \\
\quad 1976\end{array}$ \\
\hline $\begin{array}{l}\text { Limited foraging } \\
\text { opportunities (body } \\
\text { size) }\end{array}$ & $\begin{array}{l}\text { Because the capacity to store energy as fat increases with overall body size more } \\
\text { quickly than does metabolic rate, larger individuals are better able to survive long } \\
\text { periods of inclement weather, which preclude foraging, regardless of food } \\
\text { availability. Hence, smaller individuals are more likely to migrate away from their } \\
\text { breeding site during the season with most inclement weather events (applies mostly } \\
\text { in the tropics). }\end{array}$ & Boyle 2008; Boyle et al. 2010 \\
\hline Dominance & $\begin{array}{l}\text { Socially dominant individuals gain priority access to food or other resources, during } \\
\text { periods of limitation. Hence, socially subordinate individuals are more likely to } \\
\text { migrate to avoid the negative consequences of intraspecific competition. }\end{array}$ & $\begin{array}{l}\text { Fretwell 1969; Ketterson and Nolan } \\
\text { 1976; Gauthreaux Jr } 1982\end{array}$ \\
\hline Arrival time & $\begin{array}{l}\text { Because the benefits of territory acquisition vary across individuals, those with the } \\
\text { greatest incentive to compete for breeding territories are less likely to migrate. }\end{array}$ & Ketterson and Nolan 1976 \\
\hline Competitive asymmetry & $\begin{array}{l}\text { Selection to maintain residency on breeding grounds during winter varies non-linearly } \\
\text { with individual competitive ability. Because the least competitive individuals are } \\
\text { unlikely to successfully defend high-quality territories, and the most competitive } \\
\text { individuals are able to migrate and still acquire a high-quality breeding territory upon } \\
\text { return, individuals of intermediate competitive ability have the greatest incentives to } \\
\text { remain year-round residents on their breeding grounds and compete for territories in } \\
\text { spring. }\end{array}$ & This paper \\
\hline
\end{tabular}

not mutually exclusive (or necessarily exhaustive), testing some of them simultaneously in the same system would likely identify which factors are most important in mediating individual migratory decisions and how individuals balance the condition-dependent costs and benefits of different migratory strategies. Few previous studies have tracked marked animals to determine their individual migratory decisions and linked those to individual morphological, behavioral, or condition-related traits other than simply age or sex (but see Adriaensen and Dhondt 1990; Middleton et al. 2006; Gillis et al. 2008; Hegemann et al. 2015; Jahn et al. 2010; Boyle et al. 2011; Palacín et al. 2011; Norbu et al. 2013; Grist et al. 2014, 2017, Perez et al. 2014; Pratt et al. 2017; Chambon et al. 2018). These studies have greatly enhanced our understanding of the causes of migration, but none have examined the association between individual migratory tendency and a large suite of traits predicted to affect migration behavior based on mechanisms underlying the major hypotheses proposed to explain partial migration. Our goal was to gain insight into the cause(s) of partial migration in birds, especially those undertaking shortdistance facultative migrations, by explicitly testing predictions of the most common hypotheses using yelloweyed juncos (Junco phaeonotus) as our study system.
Yellow-eyed juncos are short-distance altitudinal migrants that live year-round in isolated "sky island" mountain ranges of southeastern Arizona (Phillips et al. 1964; Horvath and Sullivan 1988). Female yellow-eyed juncos are more likely to migrate downslope during winter months than males, as predicted by all five condition-dependent hypotheses (Lundblad and Conway 2020). Migratory tendency is also positively associated with breeding site elevation; those breeding at the highest elevations are the most likely to migrate downslope during the winter (Lundblad and Conway 2020). We used repeated winter surveys of an individually marked population to classify the individual migratory tendency of 286 juncos during two winters and along a $1000-\mathrm{m}$ elevational gradient. We took advantage of this system to: (1) test predictions of the four most common condition-dependent hypotheses to explain partial migration (the dominance, arrival time, thermal tolerance, and fasting endurance hypotheses; Tables 1 and 2) by examining the morphological, behavioral, and reproductive traits associated with individual migratory behavior, (2) examine the relative importance of climatic factors that constrain high-elevation winter residency by yellow-eyed juncos (and, in doing so, differentiate between the mechanisms invoked by the 
thermal tolerance and fasting endurance hypotheses), and (3) validate the assumption of the body sizerelated hypotheses that small differences in body size can affect overwinter survival.

\section{Predictions tested and rationale}

Three hypotheses that have been proposed to explain partial migration invoke body size, and all three predict that body size should be negatively correlated with migratory tendency even after controlling for sex (for all predictions, see Table 2). Downslope migration is asynchronous in our system. Individuals can quickly migrate up and down our elevation gradient in response to changing weather conditions, providing an opportunity to tease apart the thermal tolerance and fasting endurance hypotheses. The thermal tolerance (body size) hypothesis predicts that the proportion of individual juncos that are present on their breeding site at any given time during the winter should be positively correlated with recent minimum temperatures more strongly than with snow cover or depth. The fasting endurance (body size) hypothesis predicts that the proportion of individual juncos that are present on their breeding site at any given time during the winter should be negatively correlated with snow cover or depth more strongly than with recent minimum temperatures. We did not explicitly test predictions of the limited foraging opportunities hypothesis because we did not expect it to apply in our temperate-zone system (Boyle et al. 2010). Finally, we tested an underlying assumption of all three body size-related hypotheses by comparing the body size of individuals that apparently survived at least one winter in our study area to those that we only detected during a single breeding season (and are assumed to have died, thereafter). The body size-related hypotheses imply that either: (1) smaller individuals mitigate their reduced survival probability by migrating to a more benign climate during the winter and pay a reproductive cost by doing so, or (2) individuals employ an intermediate strategy whereby they balance their survival prospects with the potential reproductive benefits of not migrating and therefore employ risky strategies (as suggested by Boyle 2008; Kokko 2011). Hence, these hypotheses assume that body size will be negatively correlated with migratory tendency, positively correlated with survival, or both.

The dominance hypothesis predicts that individual aggressiveness or plumage brightness (two indices of social dominance) should be negatively correlated with migratory tendency. These predictions assume that: (1) aggressiveness and plumage brightness are directly associated with dominance rank in yellow-eyed juncos (as in Balph et al. 1979; Ketterson 1979; Belthoff and Gauthreaux 1991a) and (2) dominance and aggressiveness measures reflect behavioral syndromes that are consistent across different seasons and contexts (Sih et al. 2004; Duckworth 2006). The dominance hypothesis also predicts that stored fat levels should be positively correlated with migratory tendency among juncos recaptured early in spring based on the assumption that subordinate individuals store more fat than dominant individuals because the later achieve priority access to food and storing fat has costs for birds with predictable access to food (Norberg 1981; Lima 1986; Witter and Cuthill 1993). Therefore, the dominance hypothesis predicts that subordinate individuals might both be forced to migrate and take on more stored fat (Higginson et al. 2012; Macdonald et al. 2016).

Table 2 Predictions of four condition-dependent hypotheses tested in this study to explain intraspecific variation in migratory tendency among yelloweyed juncos

\begin{tabular}{|c|c|c|}
\hline Hypothesis & Prediction & Supported? \\
\hline \multirow{3}{*}{$\begin{array}{l}\text { Thermal tolerance } \\
\text { (Body size) }\end{array}$} & Body size should be negatively associated with migratory tendency, even within sex classes. & Y (males) \\
\hline & $\begin{array}{l}\text { The proportion of individually marked juncos persisting on their breeding site during winter-season surveys } \\
\text { should be more strongly associated (positively) with ambient temperature during prior day(s) than with } \\
\text { snow depth. }\end{array}$ & $\mathrm{N}$ \\
\hline & $\begin{array}{l}\text { Juncos detected on the same breeding site during two consecutive breeding seasons ("survivors") should be } \\
\text { larger than juncos only detected during a single breeding season ("non-survivors"). }\end{array}$ & Y \\
\hline \multirow{3}{*}{$\begin{array}{l}\text { Fasting endurance } \\
\text { (Body size) }\end{array}$} & Body size should be negatively associated with migratory tendency, even within sex classes. & Y \\
\hline & $\begin{array}{l}\text { The proportion of juncos persisting on their breeding site during winter should be more strongly associated } \\
\text { (negatively) with snow depth than with ambient temperature during prior day(s). }\end{array}$ & Y \\
\hline & $\begin{array}{l}\text { Juncos detected on the same breeding site during two consecutive breeding seasons ("survivors") should be } \\
\text { larger than juncos only detected during a single breeding season ("non-survivors"). }\end{array}$ & Y \\
\hline \multirow[t]{3}{*}{ Dominance } & Aggressiveness should be negatively correlated with migratory tendency. & $\mathrm{N}$ \\
\hline & Plumage brightness should be negatively correlated with migratory tendency. & Suggestive \\
\hline & $\begin{array}{l}\text { Among juncos recaptured in early spring (March-April), stored fat content should be positively correlated } \\
\text { with migratory tendency. }\end{array}$ & $\mathrm{Y}$ \\
\hline \multirow[t]{2}{*}{ Arrival time } & Probability of nest success should be negatively associated with migratory tendency. & Y (females) \\
\hline & Nestling growth rates should be negatively correlated with parental migratory tendency. & $\mathrm{N}$ \\
\hline
\end{tabular}


Previous tests of the arrival time hypothesis have assumed that whichever sex is responsible for establishing and defending breeding sites or territories should show lower migratory tendency to optimize their ability to compete for territories. However, if territory and mate quality vary the arrival time hypothesis also predicts differences in migratory behavior within sex classes (including among females; Creighton 2001; Kokko et al. 2006). Specifically, the arrival time hypothesis predicts that indices of territory quality (we used the probability of nesting success and nestling growth rates) should be negatively associated with migratory tendency. That is, individuals that occupy the highest-quality territories (as indicated by reproductive success) should have the greatest incentives to remain on or near those territories throughout the winter or as long as possible by departing late, arriving early, or even foregoing migration. Additionally, individuals that overwinter on or near high-quality breeding territories should again occupy the highest-quality territories and achieve the greatest reproductive success in the following breeding season.

\section{Methods}

\section{Field methods}

Study area We examined migratory behavior of yellow-eyed juncos throughout their annual cycle from May 2011-July 2013, in the Santa Catalina Mountains of southeastern Arizona (study area described by Kirkpatrick and Conway 2010; Lundblad and Conway 2020). We captured juncos at five locations along a continuous elevational gradient, ranging from 1755 to $2791 \mathrm{~m}$, during the 2011 and 2012 breeding seasons. Each of the five locations spanned a range of elevation and, together, represented a nearly complete continuum along the 1000-m elevational gradient of the junco's breeding range: 1755-1810 m (Middle Bear Canyon), 2110-2205 m (Rose Canyon Lake), 2230-2425 m (Marshall Gulch), 23352560 m (Upper Sabino Canyon), and 2690-2791 m (Lemmon Park). The straight-line distance between our highest and lowest study sites was approximately $12 \mathrm{~km}$, and a single paved road provided easy access among them.

The vegetation at our study sites ranges from Madrean pine-oak woodlands at the lowest-elevation sites to mixedconiferous woodlands at the upper sites. Annual precipitation in our study area has a bimodal pattern with the bulk of precipitation falling during the summer "monsoon" season and during infrequent winter storms. Winter precipitation varies among years (more so than at other seasons; McDonald 1956) in accordance with the El Niño-Southern Oscillation cycle and is positively associated with elevation. Average annual precipitation increases from $<30 \mathrm{~cm}$ on the valley floor at $806 \mathrm{~m}$ (National Weather Service 2017b) to $>75 \mathrm{~cm}$ at the summit (where our highest elevation site was located)
(Western Regional Climate Center 2017). Juncos are exclusively granivorous during the winter, but snow cover may prevent access to seeds. Snowfall on our study sites often melts quickly but sometimes persists for weeks or months, especially at higher elevations and on shaded or north-facing slopes. We compiled seasonal climate data from the nearest weather station (38 km from our nearest study site; National Weather Service 2017a) to compare relative temperatures and precipitation during the two winters encompassed by our study.

We captured adult and juvenile juncos in mist nets at or near active nests. We measured tarsus length, wing chord length, tail length, head length, head width, body mass, and fat content of all adult juncos. We used behavioral observations (i.e., of nesting or singing birds) and the presence of cloacal protuberances and brood patches to sex each junco. We attached an aluminum USGS leg band and a unique combination of colored plastic leg bands to each junco. We found and monitored junco nests on our study sites throughout two breeding seasons (2011 and 2012). We checked nests every 1 - 3 days with the shorter intervals occurring when we anticipated transitions between nest stages. In 2012, we measured tarsus length, wing chord length, and body mass for each nestling in each brood on the fourth and eighth day post-hatching (at nests found prior to day four of the nestling stage and when hatch date could be determined to within a half day).

Occupancy surveys We documented migratory behavior of marked juncos through intensive area searches (Ralph et al. 1993), or censuses, of each study site throughout the year. Juncos' habit of foraging on the ground, often in small flocks (outside the breeding season), and their frequent vocalizations render them relatively easy to detect and ideal for this survey technique. We surveyed each site every 7-14 days beginning in September 2011 (except Middle Bear Canyon was only surveyed beginning in Apr 2012). We surveyed each study site for as long as needed until we felt confident that we had detected all juncos present and had recorded the color-band combination of all banded juncos.

We monitored snow depth, snow cover, and ambient temperature on each study site throughout the winter of 20122013. An observer visited all nest locations within the study site concurrent with each junco survey. We visually estimated the percent snow cover within a 25 -m radius circle centered on the nest location and used a graduated rod to rapidly measure snow depth at one point $5 \mathrm{~m}$ from the nest site and in a randomly chosen direction. A second observer used the lineintercept method (Kaiser 1983) to more-intensively quantify snow cover and took depth measurements every $10 \mathrm{~m}$ along a $50-\mathrm{m}$ randomly placed line, on a subset of the same territories. We systematically deployed 111 temperature-logging iButton 
"thermochron" data-loggers (model DS1922, Maxim Integrated, San Jose) across the five study sites. We programmed the thermochrons to record ambient temperature every $60 \mathrm{~min}$.

\section{Analytical methods}

Classification of individual migratory behavior We expected that migration in our study system would be incremental (i.e., typical of facultative migration; Terrill and Able 1988; Newton 2012) rather than synchronized. Hence, we assigned each junco a migration score ranging from zero (the least migratory individuals) to four (the most migratory individuals) corresponding to the number of winter months (defined as October-January) they were absent from their breeding or natal site (Lundblad 2014).

General analytical approach We treated the general linear model, Migration Score $\sim$ Year + Sex + Elevation + Elevation $^{2}$, as an informed null model against which to test each of four mechanistic hypotheses because migratory tendency in juncos in our system is associated with year, sex, and breeding site elevation (Lundblad and Conway 2020). We used AICc to compare the informed null model, fitted with a Gaussian error distribution, to the same model with a Poisson error distribution. The Gaussian model performed substantially better $(\triangle \mathrm{AICc}=$ 457) than the Poisson model, hence we used the Gaussian model for the analysis. We used migration scores as our response variable. For 66 individuals who received migration scores during both winters (i.e., those present on the same site during three consecutive breeding seasons), we randomly chose the migration score from 1 year to avoid pseudoreplication. We then tested the thermal tolerance, fasting endurance, dominance, and arrival time hypotheses by using likelihood ratio tests to compare the informed null model to nested models that included variables predicted to reflect each mechanistic hypothesis. The previously observed effect of sex on migratory tendency could be explained either by males' larger body size, their social dominance over females, or their greater incentives to maintain territories over the winter, but each of the hypotheses predicts that their underlying mechanisms should also mediate differences in migratory tendency within sexes. Because the observed effect of sex on migratory tendency could reflect any of the four condition-dependent hypotheses, we also compared models representing each mechanistic hypothesis to a reduced null model excluding sex (Migration Score $\sim$ Year + Elevation + Elevation ${ }^{2}$ ).

We performed all statistical analyses in R (R Core Team 2017). We performed likelihood ratio tests in the lmtest package (Zeileis and Hothorn 2002) and AICc-based model selection in the package MuMIn package (Barton 2017). We checked model assumptions by: (1) plotting the residuals versus the fitted values of our informed null and reduced null models, which revealed a high degree of linearity and lack of serious heteroscedasticity, (2) plotting the residuals by sex, year, and elevation, which again revealed similar variances, and (3) by visually inspecting histograms of the residuals, which showed no serious deviations from normality. We also used an alternative logistic regression-based approach where the binomial response variable was whether or not each marked junco was present on each survey of its respective study site and including subject ID as a random effect. We then modeled presence/absence as a function of the same set of predictor variables considered in the original approach (above) plus the absolute number of days that the survey fell from the winter solstice. The results of this second analytical approach were very similar to those presented here and are not discussed further. Migration scores were based on outcomes calculated objectively at the end of the study based on observations during many site surveys and, hence, were effectively blind. Explanatory variables were recorded blind with respect to migratory status of focal birds.

Tests of the fasting endurance and thermal tolerance hypotheses Some previous studies have criticized univariate measures and recommended multivariate approaches to summarizing overall body size (e.g., Rising and Somers 1989). We used principal component analysis (based on single value decomposition and implemented with the built-in $\mathrm{R}$ function, "prcomp") to generate a single summary index of body size that pooled variation in five structural body size measurements: tarsus length, wing chord length, tail length, head length, and head width. PC1 accounted for $31.8 \%$ of the total variance in body size (Lundblad and Conway 2020). We then used one-sided Welch's $t$ tests to test the directional prediction that metrics of body size (body size PC1, each univariate structural measurement, body mass, and body fat) differed between adult juncos that apparently survived a winter (those detected on the same site during two breeding season) and those that did not (those that were only detected during a single breeding season). We conducted these tests separately for males and females, because annual survival and body size differed between sexes.

Our two methods for measuring percent snow cover were strongly correlated $(r=0.96, n=21, P<0.001)$ as were our two methods for measuring snow depth $(r=$ $0.64, n=21, P=0.002)$. Thus, we used our rapid estimates of snow cover and snow depth, averaged across territories at a study site, as our metrics of snow cover and snow depth during each survey. We calculated the average minimum temperature recorded at each of the five sites during the 24- and 72-h periods prior to each junco survey. We considered the two different time frames 
because we wanted to account for thermal stress that affects migratory decisions and may be cumulative across $>$ 1 day. We used preliminary AICc-based model selection (Burnham and Anderson 2002) to screen and select the top performing temperature variable (minimum temperature during the $72 \mathrm{~h}$ before each survey) and the top performing snow variable (snow depth). We then pooled all junco survey data (i.e., for all five study sites) from the winter of 2012-2013 and used weighted logistic regression to model the proportion of juncos present on their breeding site during each winter survey as a function of three possible predictors: (1) average snow depth at that site on the day of each survey, (2) minimum temperature at that site during the $72 \mathrm{~h}$ preceding each survey, and (3) the duration of each survey. The correlation between snow depth and 72-h minimum temperature $(r=0.69, n=65$, $P<0.001)$ was not excessive, so we felt comfortable including these variables in the same model.

Tests of the dominance hypothesis We presented a taxidermically mounted yellow-eyed junco and broadcast junco advertisement songs $5 \mathrm{~m}$ from junco nests, during incubation, to simulate territorial incursions and measure aggressiveness (Järvi et al. 1987; Sogge et al. 2007; our full experimental procedures are described in Lundblad 2014). We classified junco aggressiveness on a 15-point scale, using a scoring rubric that considered a full suite of aggressive behaviors. Focal juncos received 5 points if they approached the mount within a circumference of less than $1 \mathrm{~m}$ at any point during the 5-min trial. They received 4 points for a minimum approach distance of 1-3 m, 3 points for a minimum approach distance of 3$10 \mathrm{~m}$, and 2 points for a minimum approach distance of greater than $10 \mathrm{~m}$ (i.e., all focal juncos that moved closer to the mount from their starting position received a minimum score of 2). Focal juncos received an additional 2 points if they approached the mount on the ground at less than $3 \mathrm{~m}$ or 1 additional point for an on the ground approach from 3 to $10 \mathrm{~m}$. Individuals received 2 additional points if they responded by changing their behavior (i.e., flying into the area from outside the observers' range of vision, approaching the mount, countersinging, or any other aggressive behavior) within the first $30 \mathrm{~s}$ of song broadcast or 1 additional point for responding during the first $60 \mathrm{~s}$ of song broadcast. Focal juncos received 1 additional point for each of the following behaviors: circling the mount on the ground at least once at less than $5 \mathrm{~m}$, making dives over the top of the mount within a $3-\mathrm{m}$ radius, and countersinging (males only) against the broadcast. Focal juncos received 2 additional points for a visible response lasting more than $4 \mathrm{~min}$ or 1 point for a visible response lasting 2-4 min. Individuals that physically attacked and made contact with the mount received the maximum score of 15 , and we discontinued the trial on those occasions $(n=4)$ to prevent damage to the mount. A focal junco that exhibited no visible response to the experiment or moved further away from the mount following the initiation of playback received a score of 1 .

The amount of rufous color in the wings of yellow-eyed juncos varies among individuals, and plumage signals are thought to reflect dominance hierarchies in juncos (Balph et al. 1979; Ketterson 1979). A single observer (CGL) examined photos of the dorsal wing surface of 86 adult juncos, ordered them from dullest to brightest, and placed them into bins ranging from one (dullest) to five (brightest) based on the number of tertial feathers and wing coverts with rufous and the extent of rufous on each feather. We used one-sided Welch's $t$ tests to test the expectations that male juncos had brighter plumage and were more aggressive than female juncos. We calculated the Pearson correlation coefficients between migration scores and: (1) body fat content, (2) body mass, and (3) body mass divided by wing chord length for each individual junco that we first captured during the 2011 breeding season and then recaptured on the same study site at the start of the subsequent breeding season (i.e., March-April 2012).

Tests of the arrival time hypothesis We calculated the probability of nesting success for individual juncos as the number of days each nest survived (from initiation to either fledging or failure) divided by the average length of the nesting cycle (26.2 days) for a successful nest in our study (Fontaine et al. 2007). We examined the relationship between the probability of nesting success and migratory tendency during both the previous and following winters. We calculated the average of each of the three nestling growth parameters (tarsus length, wing chord length, body mass) for all nestlings in each brood on the fourth and eighth day after hatching. We calculated a normalized slope for each of the three growth parameters and then averaged them into an overall nestling growth rate index for each brood. We used both migration scores from the previous winter and those from the following winter and then examined whether nestling growth explained additional variation (compared to the informed null) in overall migration scores.

Comparing the dominance, body size, and arrival time hypotheses Finally, we used AICc-based model selection (Burnham and Anderson 2002) to compare models best representing the dominance, arrival time, and the three body size-related hypotheses to explain variation in migratory tendency for the 62 juncos for which we measured a complete set of predictors. We compared models including all combinations of year, sex, elevation, elevation ${ }^{2}$, body size PC1, plumage brightness, and the probability of nesting success, after standardizing all the continuous predictors. We calculated the relative importance for each variable based on summed model weights. We then repeated the same procedure without sex because sex differences in 
body size, dominance, or incentives to winter on or near the wintering grounds could drive the observed sex-biased migration pattern.

\section{Data availability}

The datasets generated and analyzed during the current study are available from the corresponding author on reasonable request.

\section{Results}

We assigned migration scores to 286 individual juncos: 128 during the winter of 2011-2012 and 228 during the winter of 2012-2013 (66 juncos were assigned migration scores during both winters). We acquired a full suite of body size measurements from 318 adult juncos. We found and monitored 366 junco nests: 83 during 2011 and 283 during 2012. We measured nestling growth of 87 junco broods. We measured adult aggressiveness at 70 junco nests and assigned plumage brightness scores to 86 juncos.

Yellow-eyed juncos were more likely to migrate during the winter of 2011-2012 than during the winter of 20122013 (Lundblad and Conway 2020), but this annual difference was stronger among adult males than among adult females and hatch-year juncos (Fig. 1). Among the 66 individuals for which we had migration scores during both winters, $59.1 \%$ had lower migration scores during the second winter (2012-2013) than during the first (2011-2012), $18.2 \%$ had higher migration scores during the second winter than during the first, and $22.7 \%$ had migration scores that were the same during each winter. The proportion of individuals that had lower migration scores during the

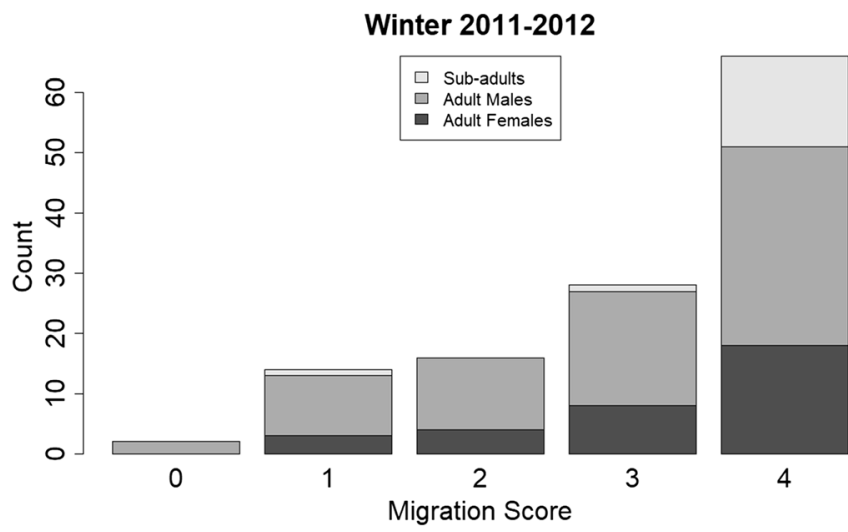

Fig. 1 Distribution of migration scores, by sex and age class, assigned to yellow-eyed juncos in the Santa Catalina Mountains of Arizona during the winters of 2011-2012 and 2012-2013, based on the number of "winter" months (October-January) each was absent from their breeding site. second winter was less pronounced with increasing study site elevation, and the proportion of individuals that had higher migration scores during the second winter became more pronounced with increasing study site elevation, although these elevational trends were not significant $\left(\chi_{3}^{2}=\right.$ 5.7, $P=0.13$; Table 3).

Precipitation during the first winter $(37 \%$ above the 1981-2010 average, from September 2011-February 2012) was $240 \%$ of that that fell during the second winter $(43 \%$ below the 1981-2010 average, from September 2012-February 2013). The proportion of that SeptemberFebruary precipitation that fell during fall (i.e., prior to December) was 0.75 during the first winter versus 0.12 during the second winter. The average SeptemberFebruary temperature was nearly identical in each of the two winters $\left(16.9{ }^{\circ} \mathrm{C}\right.$ and $17.1{ }^{\circ} \mathrm{C}$ in $2011-2012$ and 2012-2013, respectively).

Tests of the fasting endurance and thermal tolerance hypotheses Male juncos were larger than females (Welch's $\left.t_{243.6}=-14.0, P<0.001\right)$. The model including an interaction between body size and sex explained more variation in migratory tendency than the informed null $\left(\chi^{2}{ }_{1}=6.5, P=0.039\right)$. Larger males were less likely to migrate than smaller males (as predicted by all three body size-related hypotheses), but body size was not associated with migration tendency in females (Fig. 2). When both sexes were pooled, body size explained significantly more variation in migratory tendency of all juncos, compared to the reduced null model (i.e., when sex was excluded from the null; $\chi^{2}{ }_{1}=11.8, P<0.001$ ). The association between body size and migratory tendency was again negative $(\beta=-0.27, \mathrm{SE}=0.08,95 \%$ $\mathrm{CI}=-0.43--0.12)$, when considering both sexes pooled.

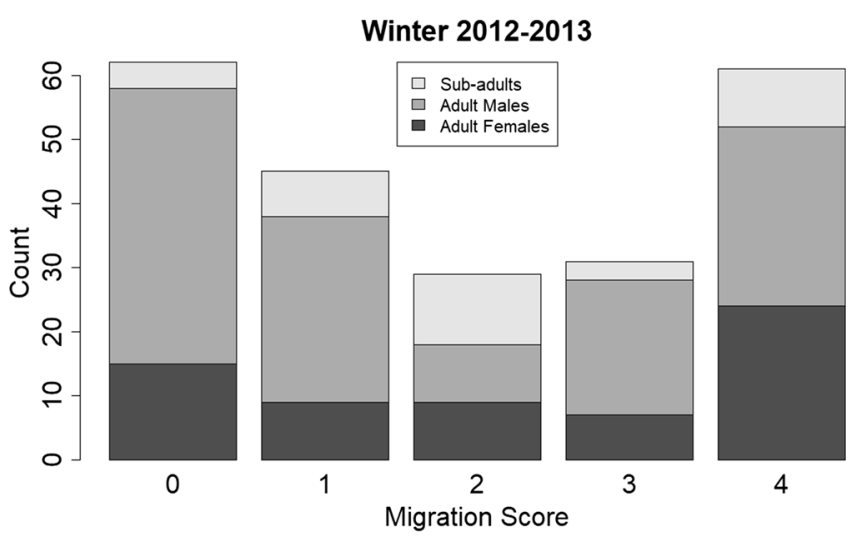

Higher migration scores indicate higher migratory tendency, and y axes display counts. Females and sub-adults employed similar strategies during each year, but adult males were far more likely to migrate during the winter of 2011-2012 than during the winter of 2012-2013 
Table 3 Distribution of changes in migration score (from -4 to +4 ) between the winter of 2011-2012 and the winter of 2012-2013 by yellow-eyed juncos in the Santa Catalina Mountains. Positive values indicate individuals that were more migratory during the second winter than the first, and negative values indicate individuals that were less migratory during the second winter than the first

\begin{tabular}{|c|c|c|c|c|c|c|c|c|c|c|c|c|c|c|}
\hline \multirow[b]{2}{*}{ Site } & \multicolumn{9}{|c|}{$\begin{array}{l}\text { Change in migration score } \\
\text { from } 2011 \text { to } 2012 \text { to } 2012-2013\end{array}$} & \multirow{2}{*}{$\begin{array}{l}\text { No. less } \\
\text { migratory } \\
\text { in 2012-2013 }\end{array}$} & \multirow{2}{*}{$\begin{array}{l}\text { No. more } \\
\text { Migratory } \\
\text { in 2012-2013 }\end{array}$} & \multirow{2}{*}{$\begin{array}{l}\% \text { less } \\
\text { migratory } \\
\text { in 2012-2013 }\end{array}$} & \multirow{2}{*}{$\begin{array}{l}\% \text { more } \\
\text { migratory } \\
\text { in 2012-2013 }\end{array}$} & \multirow{2}{*}{$\begin{array}{l}\% \text { changed } \\
\text { in } 2012- \\
2013\end{array}$} \\
\hline & -4 & -3 & -2 & -1 & 0 & 1 & 2 & 3 & 4 & & & & & \\
\hline Rose Canyon Lake & 1 & 2 & 4 & 3 & 5 & 1 & 0 & 0 & 0 & 10 & 1 & $62.5 \%$ & $6.3 \%$ & $68.8 \%$ \\
\hline Marshall Gulch & 1 & 2 & 2 & 3 & 2 & 1 & 0 & 0 & 0 & 8 & 1 & $72.7 \%$ & $9.1 \%$ & $81.8 \%$ \\
\hline $\begin{array}{l}\text { Upper Sabino } \\
\text { Canyon }\end{array}$ & 0 & 2 & 3 & 2 & 2 & 0 & 1 & 0 & 0 & 7 & 1 & $70.0 \%$ & $10.0 \%$ & $80.0 \%$ \\
\hline Lemmon Park & 2 & 3 & 5 & 4 & 6 & 5 & 2 & 1 & 1 & 14 & 9 & $48.3 \%$ & $31.0 \%$ & $79.0 \%$ \\
\hline Overall & 4 & 9 & 14 & 12 & 15 & 7 & 3 & 1 & 1 & 39 & 12 & $59.1 \%$ & $18.2 \%$ & $77.3 \%$ \\
\hline
\end{tabular}

Body size also affected apparent survival. Female juncos that were detected during two consecutive breeding seasons had larger body size $(\mathrm{PC} 1)\left(t_{116.4}=-1.8, P=0.035\right)$ and $1.0 \%$ longer wings $\left(t_{113.4}=-1.8, P=0.041\right)$ than those that went undetected during a subsequent breeding season (i.e., assumed mortalities). Male juncos that were detected during two consecutive breeding seasons also had $1.0 \%$ longer wings than apparent mortalities $\left(t_{91.1}=-2.2, P=0.015\right)$, but overall body size (PC1) did not differ between survivors and non-survivors. No other univariate measurements differed between survivors and non-survivors, for either sex. The probability that a junco persisted on its breeding site during any given winter survey was negatively associated with snow depth $(\beta=-0.62, \mathrm{SE}=$ $0.07, Z_{60}=-9.2, P<0.001$; Fig. 3a), but not with $72-\mathrm{h}$ minimum temperature $\left(Z_{60}=-1.1, P=0.284\right.$; Fig. $\left.3 b\right)$.

Tests of the dominance hypothesis Fat content in spring (March-April) was positively correlated with migratory tendency the prior winter $(r=0.33, n=58, P=0.01)$ and especially among males $(r=0.47, n=36, P=0.004)$, but body mass $(r=-0.13, n=58, P=0.34)$ and body mass/wing chord length were not $(r=-0.07, n=58, P=0.61)$. Male juncos were more aggressive towards simulated territorial incursions than were females (Welch's $t_{68}=-5.67, P<0.001$ ). Aggressiveness did not explain variation in migratory tendency better than the informed null $\left(\chi^{2}{ }_{1}=1.5, P=0.216\right)$ or the reduced null model $\left(\chi_{1}^{2}=0.5, P=0.485\right)$. Including quadratic effects and interaction terms did not change the results; the null models without aggressiveness still performed better. Males had brighter plumage than females (Welch's $t_{51.5}=-$ $3.2, P=0.001)$. We found some evidence that plumage brightness explained more variation in migratory tendency than the informed null $\left(\chi_{3}^{2}=7.1, P=0.069\right)$ and the reduced null $\left(\chi_{3}^{2}=8.2, P=0.042\right)$ when we included an interaction between plumage brightness and the date it was measured. Brighter individuals were less migratory than duller
Fig. 2 The model-predicted migratory tendency of yellow-eyed juncos breeding in the Santa Catalina Mountains of Arizona from 2011-2013 declined with increasing body size among males ( $n=184$; solid line) but not among females $(n=125$; dotted line). Year is set to the winter of 2011-2012, and elevation is held at its mean. PC1 is an index summarizing pooled variation in 5 structural body size measurements (tarsus length, tail length, wing chord length, head width, and head length), and shaded regions represents $95 \%$ confidence intervals

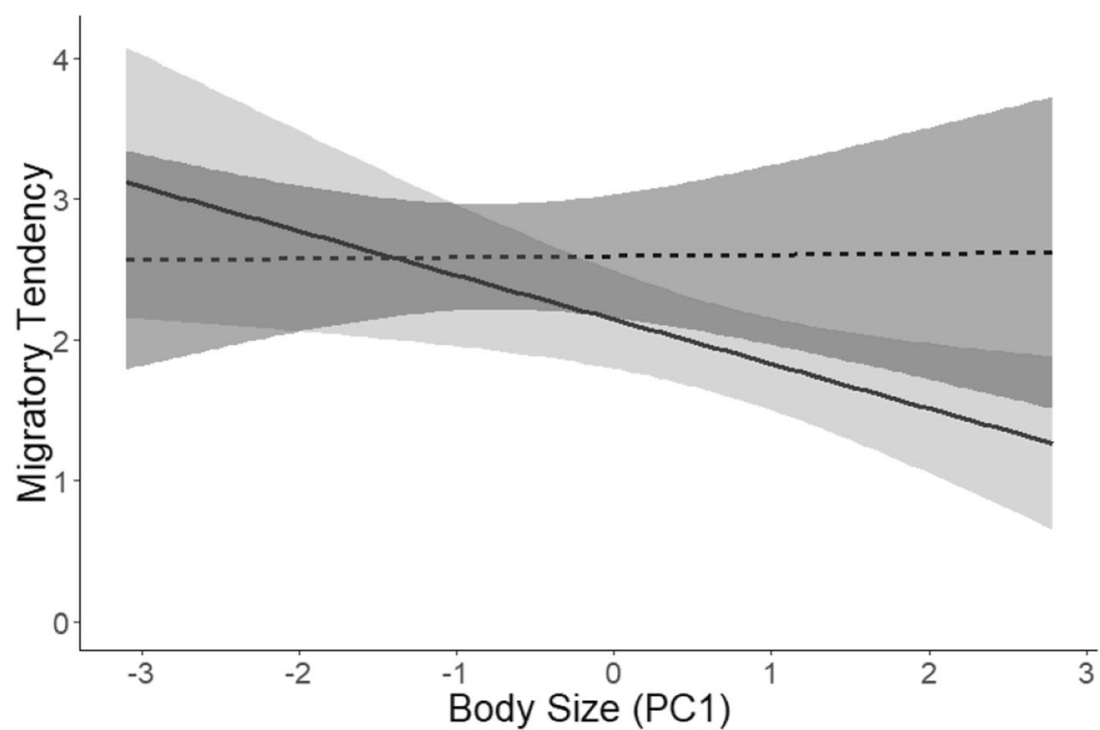




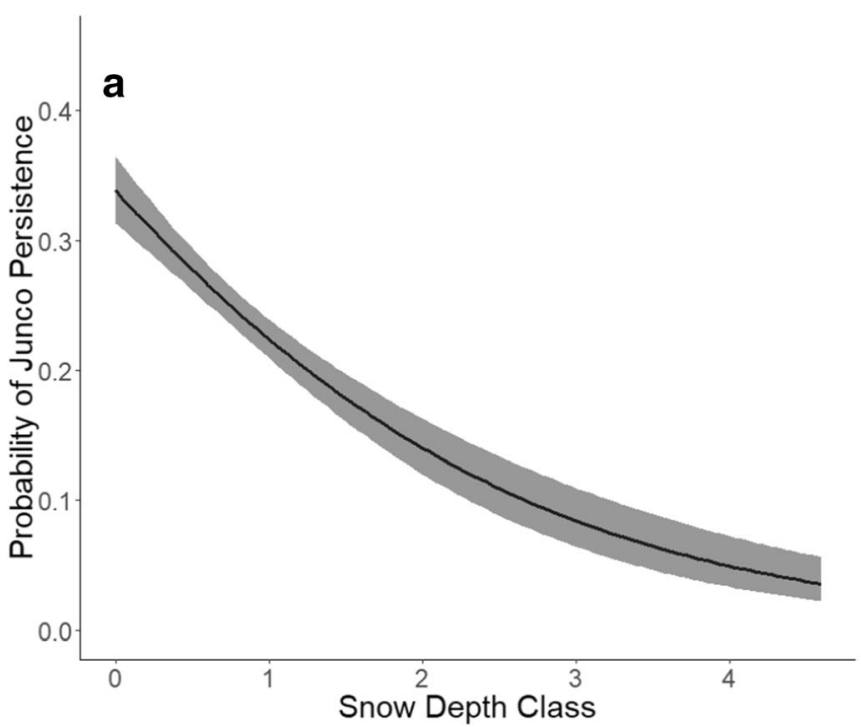

Fig. 3 The model-predicted probability that an individual junco $(n=286)$ persisted on its breeding site during winter-season surveys (every 714 days, October 2012-January 2013) in the Santa Catalina Mountains: a declined with increasing snow depth on its respective study site (classes:

individuals for those measured earlier in the season, but the relationship was not apparent later in the season (Fig. 4).

Tests of the arrival time hypothesis The probability of nesting success was not associated with male migratory tendency during the previous winter $\left(\chi^{2}{ }_{1}=0.05, P=0.818\right.$; compared to the informed null model) but was associated with male migratory tendency during the following winter $\left(\chi^{2}{ }_{1}=4.32, P=\right.$ 0.038; compared to the informed null) (Fig. 5). Males with higher nesting success were more migratory $(\beta=1.27, \mathrm{SE}=$ 0.62 ) during the following winter, opposite of the prediction of the arrival time hypothesis. The model that included the

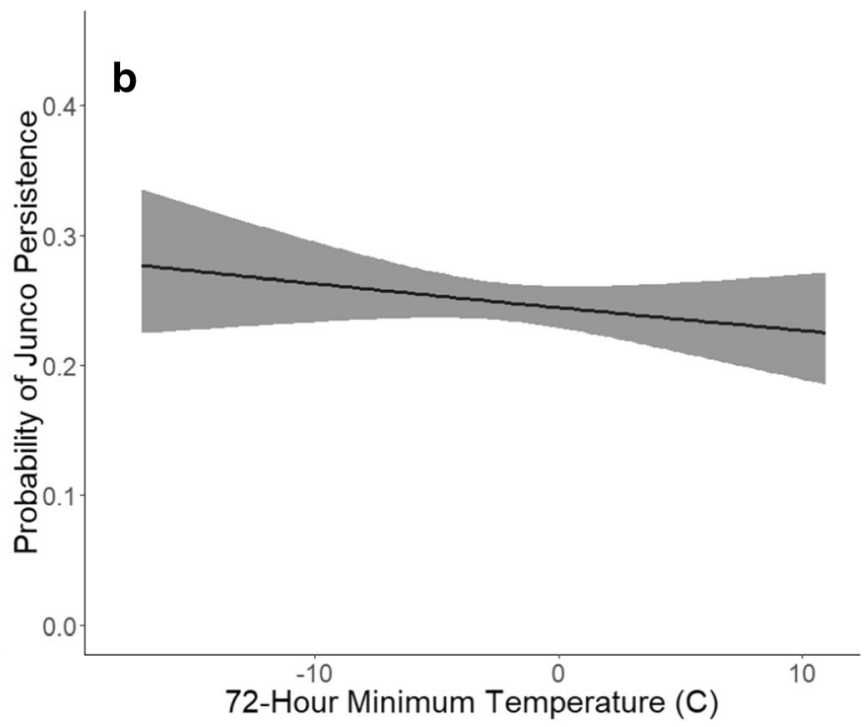

(0) none, (1) 0-1 dm, (2) 1-3 dm, (3) 3-6 dm, (4) > $6 \mathrm{dm}$ ) and b was not significantly associated with the minimum temperature during the previous $72 \mathrm{~h}$. Shaded regions represent $95 \%$ confidence intervals

probability of nesting success explained more variation in female migratory tendency during the previous winter than the informed null $\left(\chi_{1}^{2}=6.09, P=0.014\right)$. Females who experienced higher nesting success were less likely to have been migrants during the previous winter $(\beta=-1.02, \mathrm{SE}=0.43$, Fig. 5a), as predicted by the arrival time hypothesis. The probability of nesting success did not explain more variation in female migratory tendency during the following winter compared to the informed null model $\left(\chi_{1}^{2}=0.44, P=0.507\right.$; Fig. $5 b)$. Nestling growth rates did not explain additional variation in migratory tendency among males $\left(\chi_{1}^{2}=0.25, P=0.622\right)$ or among females $\left(\chi_{1}^{2}=0.26, P=0.610\right)$, compared to the
Fig. 4 Among yellow-eyed jun$\cos (n=86)$ breeding in the Santa Catalina Mountains of Arizona, model-predicted migratory tendency was negatively correlated with plumage brightness. Year is set to the winter of 2011-2012, and elevation is held at its mean. Brighter individuals were less likely to migrate than duller individuals, but this relationship was stronger among individuals measured early in the season, when plumage was less worn, than among individuals measured later in the season. The three lines indicate capture dates: early, mid, and late portions of the nesting season

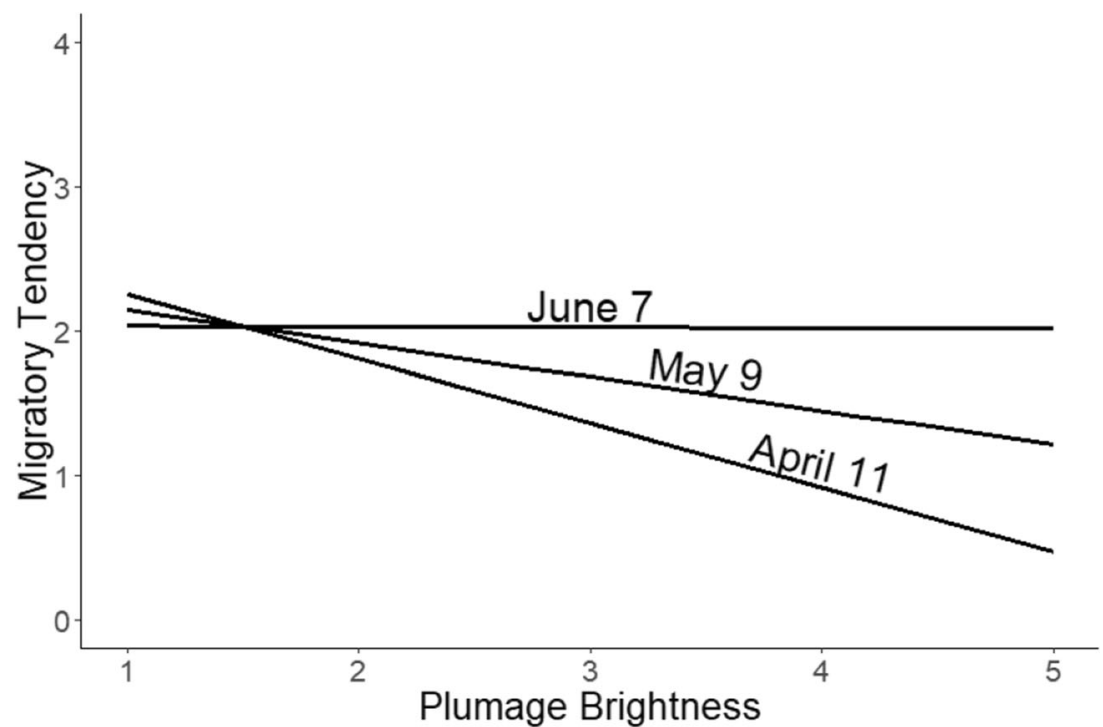




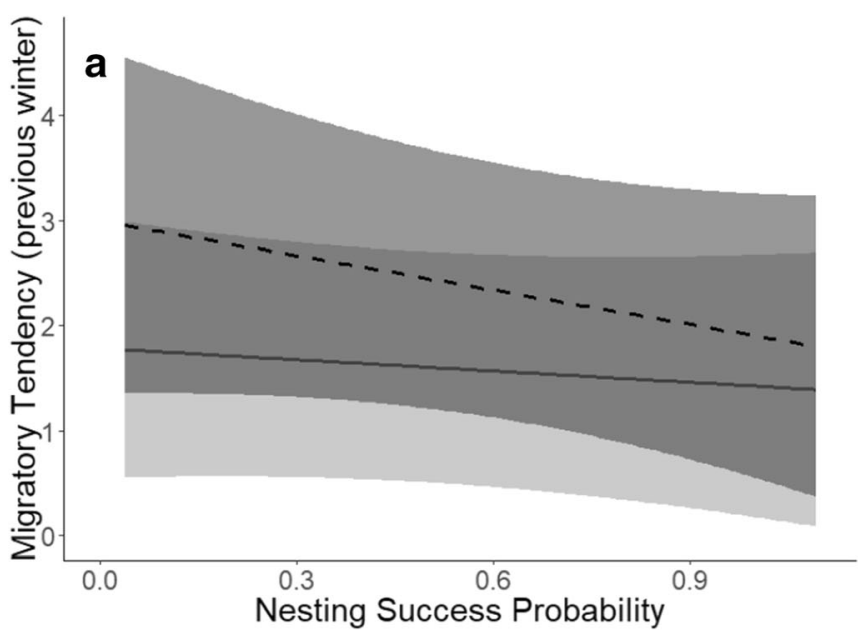

Fig. 5 The probability of nesting success was a negatively associated with the migratory tendency of female (dashed line), but not male (solid line) yellow-eyed juncos during the previous winter $(n=65)$ and $\mathbf{b}$ positively associated with migratory tendency of male (solid line) but not

informed null model. We obtained similar results regardless of whether we used only migratory tendency the prior winter, only migratory tendency the following winter, or both.

Comparing the dominance, body size, and arrival time hypotheses Models including the probability of nesting success were better supported than those with plumage brightness or body size (both when sex was included and excluded from the set of candidate models; Table 4). Models including the probability of nesting success accounted for $46 \%$ of total model weight, compared to $29 \%$ for plumage brightness and $28 \%$ for body size (Table 5 ).

\section{Discussion}

Migration is a ubiquitous animal behavior which clearly imposes several costs. So, why migrate? Particularly hard to explain is why some individuals migrate and some do not within the same population. Understanding variation in migratory behavior within species (partial and differential migration), however, can lend insight into which mechanisms underlie migration more generally (Berthold 1999). This is the first empirical study to test explicit predictions of four

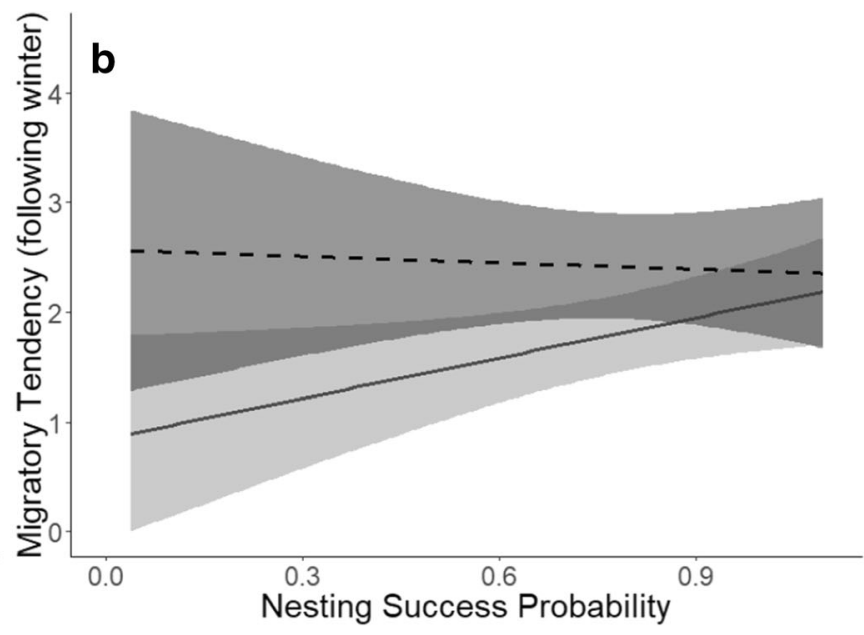

female (dashed line) yellow-eyed juncos during the following winter ( $n=$ 140). Year is set to the winter of 2011-2012, and elevation is held at its mean. Shaded regions represent $95 \%$ confidence intervals

different mechanistic hypotheses proposed to explain the underlying causes of intraspecific variation in migratory behavior (Table 2). Our results with yellow-eyed juncos are consistent with the fasting endurance and (for females) arrival time hypotheses, but not the thermal tolerance and dominance hypotheses, and suggest additional mechanisms which may mediate individual migratory decisions among males. We used a hypothetico-deductive approach that was unique because we did not rely on circular predictions regarding differences in migration among sex and age classes, we tested both experimental and correlative predictions, and we included predictions derived from each hypothesis in a single model selection exercise (to compare relative support for each of the four hypotheses). Finally, this study is among the first to examine the associations between individual migratory tendency and actual nesting success (also see Grist et al. 2017). Consequently, our study provides one of the strongest tests yet of these four hypotheses and the first effort to test the relative support of each simultaneously.

Three of our results provide particularly notable insights into the mechanisms responsible for partial migration: (1) smaller individuals are more likely to migrate even within a sex class (males), (2) larger individuals have higher probability of apparent overwinter survival within sex classes, and (3)
Table 4 Competing models (those with $\triangle \mathrm{AICc} \leq 2.0$ ) designed to explain variation in migratory tendency among 62 yellow-eyed juncos for whom we measured a full set of covariates

\begin{tabular}{|c|c|c|c|c|}
\hline Model & $k$ & $\mathrm{AICc}$ & $\Delta \mathrm{AICc}$ & $W_{\mathrm{AICc}}$ \\
\hline Migratory Tendency $\sim$ Elevation + Year + Sex & 4 & 195.5 & 0.0 & 0.11 \\
\hline Migratory Tendency $\sim$ Elevation + Year + Sex + Nest Success & 5 & 195.7 & 0.21 & 0.10 \\
\hline Migratory Tendency $\sim$ Elevation + Year & 3 & 196.4 & 0.92 & 0.07 \\
\hline Migratory Tendency $\sim$ Elevation + Year + Sex + Body Size & 5 & 197.1 & 1.64 & 0.05 \\
\hline Migratory Tendency $\sim$ Elevation + Elevation $^{2}+$ Year + Sex + Nest Success & 6 & 197.2 & 1.76 & 0.05 \\
\hline Migratory Tendency $\sim$ Elevation + Year + Nest Success & 4 & 197.5 & 2.00 & 0.04 \\
\hline
\end{tabular}


Table 5 The relative importance of predictors on the migratory tendency of yellow-eyed juncos in the Santa Catalina Mountains of Arizona from 2011-2013 among 62 individuals for which we measured a full set of covariates. Relative importance is based on cumulative model weights across a model set including all different combinations of standardized predictors

\begin{tabular}{ll}
\hline Parameter & Relative importance \\
\hline Elevation & 0.98 \\
Year & 0.91 \\
Sex & 0.60 \\
Probability nest success & 0.46 \\
Plumage brightness & 0.29 \\
Body size & 0.28 \\
Elevation $^{2}$ & 0.26 \\
\hline
\end{tabular}

size-dependent variation in fasting endurance (rather than thermal tolerance) is more likely responsible for the relationship between body size and migratory tendency. Smaller male juncos were more likely to migrate than larger individuals. The association between body size and migratory tendency was stronger when we compared the body size model to the reduced null model (the informed null model minus sex), suggesting that the female-biased migratory tendency of yelloweyed juncos in our system (Lundblad and Conway 2020) may be driven by size dimorphism. Our results suggest that winter residency by yellow-eyed juncos at high elevations is constrained by seasonal food limitation and limits to juncos' fasting endurance, rather than by physiological intolerance of cold temperatures. Although these two mechanisms have been discussed since the body size hypotheses were first proposed nearly 50 years ago (Ketterson and Nolan 1976; Ketterson and Nolan 1983; Lima 1986), few previous studies have attempted to distinguish between them. The sex ratio of wintering snow buntings (Plectrophenax nivalis) varied geographically in response to winter severity and in a pattern predicted by the body size hypotheses (Macdonald et al. 2016), but the authors were unable to infer which of the body size mechanisms (limited thermal tolerance or fasting endurance) was responsible for sex segregation. Snow cover may prevent juncos from accessing winter food resources in our system, similar to how the winter distribution of ground-feeding northern flickers (Colaptes auratus) corresponds to areas that remain relatively snow free (Gow and Wiebe 2014). Similarly, the inability to forage during prolonged storm events drives the altitudinal migrations of white-ruffed manakins (Corapipo altera) (Boyle et al. 2010) and explains community-wide altitudinal migration patterns in Costa Rica (Boyle 2011).

Juncos were more likely to migrate away from their breeding sites in the winter of 2011-2012 than during the winter of 2012-2013 (Lundblad and Conway 2020). The inter-annual differences in average migratory tendency and the observed plasticity in individual migratory behavior (among those individuals with two winters' worth of data, presented in Table 3) suggest that migratory strategies are unlikely to be genetically fixed in our system (also see Ogonowski and Conway 2009). Instead, inter-annual variation in the severity of seasonal food limitation may account for the inter-annual variation in migratory behavior. Heavier precipitation in the fall of 2011 may have limited juncos' access to food resources at higher elevations, limited their ability to forage (Boyle 2008), or have been a proximate cue of a challenging upcoming winter. Temperature during the two winters was similar, so the differences in migratory behavior between years provide additional support for the fasting endurance hypothesis (rather than the thermal tolerance hypothesis). The distinction between the thermal tolerance and fasting endurance hypotheses has implications for understanding how migratory behavior will be impacted by climate change. Under the thermal tolerance mechanism, warmer winter temperatures might reduce the need to migrate because of reduced need to avoid thermal extremes. However, climate change might also alter precipitation patterns (Pachauri et al. 2014). If climate change induces either increased snowfall (directly limiting access to seeds) or more frequent or intense precipitation events (indirectly preventing access to food by constraining foraging opportunities), birds at high elevations could have greater (instead of reduced) difficulty meeting their winter food requirements (Boyle 2008).

Our study is one of the few to examine whether migratory tendency is related to body size within sex classes (also see Prescott 1994; Jahn et al. 2010; Norbu et al. 2013; Hegemann et al. 2015; Macdonald et al. 2016), and unlike most previous studies we used a multivariate measure that is more likely to accurately reflect variation in overall body size. Large male tropical kingbirds (Tyrannus melancholicus) were more likely (not less likely) to migrate than small conspecific males in the Amazon basin (Jahn et al. 2010). Migration patterns opposite of those predicted by the body size-related hypotheses in tropical kingbirds highlight that: (1) we need to test explicit mechanistic hypotheses (thermal tolerance, fasting endurance, limited foraging opportunities, etc.) across different regions and study systems, and (2) predictions of each hypothesis may differ between temperate and tropical regions, among different foraging guilds, and across species.

Despite the fact that smaller juncos were more likely to migrate than larger juncos, body size was also positively associated with apparent overwinter survival. Our results corroborate those from other migratory species, where larger individuals had higher overwinter survival (Perrins et al. 1973; Fleischer and Johnston 1984; Lehikoinen 1986). Both long-distance neotropical migrants and short-distance migrants have higher overwinter survival than resident birds overwintering near their breeding grounds (Zúñiga et al. 2017; Dokter et al. 2018), but to our knowledge our study is the first to demonstrate that small differences in body size may 
affect survival of short-distance altitudinal migrants. Alternatively, our data could also indicate size-biased breeding dispersal where smaller individuals are more likely to disperse than larger individuals. Such a pattern might be expected if larger individuals can despotically exclude smaller subordinates (Fretwell 1972).

The dominance hypothesis received little support to explain partial migration in our system. Aggressiveness did not explain variation in migratory tendency. In contrast, some studies have reported indirect results that are consistent with the dominance hypothesis. For example, more dominant sex and age classes (males and adults) of European blackbirds (Turdus merula) were least likely to migrate (Schwabl 1983; Lundberg and Schwabl 1983) and appeared to gain priority access to limited food resources during the winter (Lundberg 1985). Moreover, younger birds that migrate early in life can become residents as they age but the opposite rarely happens (Schwabl 1983; Ogonowski and Conway 2009). Aggression could be negatively or non-linearly correlated with dominance in some species if subordinate individuals feel relatively more threatened by a would-be usurper than do dominant individuals. Moreover, other attributes besides aggressiveness (e.g., body size) might better reflect individual variation in dominance (Fretwell 1969). However, body size did not predict hierarchical dominance relationships among yellow-eyed juncos in a previous study at two of our study sites (Moore 1972). We found some support for a relationship between plumage brightness and migratory behavior in our system. The pattern was not statistically significant when sex was included in the models but was in the direction predicted by the dominance hypothesis. When sex was removed from the models, plumage brightness did explain significantly more variation in migratory behavior than the informed null model (the effect was negative) suggesting that plumage brightness might explain some of the observed sexbias in migratory tendency (Fig. 4). The interaction we observed between plumage brightness and capture date may reflect increasing feather wear across the breeding season, whereby intraspecific variation in plumage brightness was more difficult to detect later in the season. A more robust test of the relationship between plumage-based signals of dominance and migratory tendency could consider more than a single plumage trait. For example, the amount of white in the outer tail has also been shown to predict dominance hierarchies in juncos (Balph et al. 1979; Ketterson 1979).

Juncos that were more migratory carried greater fat upon recapture at their breeding site the following spring in 2012 . Larger fat stores are associated with longer fasting endurance (Calder 1974; Ketterson and Nolan 1976), but fat storage comes at the cost of reduced flight efficiency (Norberg 1981) and increased predation risk (Witter and Cuthill 1993). Therefore, birds are thought to increase stores of fat only when future food availability is uncertain (Lima 1986). Hence, subordinate migrants might store fat because dominant residents gain priority access to food resources or in preparation for return-migration to their breeding site. Alternatively, lower fat reserves among residents may simply reflect that seasonal food limitation should be more severe for residents than for migrants that move downslope.

Seasonal food limitation, exacerbated by snow cover, appears to drive downslope migration in our system, whereas spatial variation in territory quality and nest predation risk appears to drive the upslope portion of the migratory cycle (Lundblad and Conway 2020). Previous studies have found that resident individuals and those that migrate shorter distances accrue various reproductive benefits, relative to their migratory counterparts (Adriaensen and Dhondt 1990; Gillis et al. 2008; Grist et al. 2017; Lok et al. 2017), as predicted by the arrival time hypothesis. Our study is among the first to examine the associations between individual nesting success and migratory decisions during both the previous and following winters (i.e., relative to the breeding season). Female juncos (but not males) that were less likely to migrate achieved greater reproductive success during the following breeding season, as predicted by the arrival time hypothesis. Males that had greater nesting success were more migratory during the following winter. This unexpected finding could result from variation in individual quality or competitiveness (Cam et al. 2002; Kokko 2011). The arrival time hypothesis assumes that prior residency gives early-arriving (or non-migratory) individuals a competitive advantage in holding a high-quality territory that is hard for late-arriving would-be usurpers to overcome (Davies 1978; Tobias 1997). However, if prior residency is not $100 \%$ effective at preventing usurpation (as evidence suggests in some birds; Nolan 1978), the most highly competitive individuals might be able to migrate and still claim a high-quality territory in the spring (Kokko 2011). Hence, if some individuals can overcome the prior residency advantage of early-arrivers, they can forego the risks associated with overwintering on high-elevation breeding grounds without suffering fitness costs during the breeding season. Indeed, the most dominant adult males were the most likely to migrate in tropical kingbirds in the Amazon Basin (Jahn et al. 2010).

We propose a new "competitive asymmetry hypothesis" to explain intraspecific variation in migratory tendency in a population. The competitive asymmetry hypothesis posits that the optimal migration strategy is condition and frequencydependent whereby: (1) the least competitive individuals have little to gain from winter residency on or near the breeding grounds since they have limited ability to defend a territory against a returning migrant of higher competitive ability, (2) individuals of intermediate social dominance are the least migratory because prior residency gives them a competitive edge over otherwise equally-matched individuals but not over clearly dominant individuals, and (3) the most competitive and dominant individuals can migrate and still return to claim a high-quality territory. This new hypothesis builds upon ideas 
proposed by Kokko (2011) whereby migration is frequencyand condition-dependent and outcomes depend on territory acquisition rules and territory holding power (relative benefits of prior ownership). And, it incorporates the mechanisms of the three most common migration hypotheses in the literature: the dominance hypothesis, the arrival time hypothesis, and the body size hypothesis.

Alternatively, the positive association between nesting success and subsequent male migratory tendency could reflect seasonal carry-over effects (Runge and Marra 2005 ) if greater parental investment comes at the expense of self-maintenance and body condition (Marra et al. 1998; Gill et al. 2001; Bearhop et al. 2004). Hence, those parents investing more in reproduction might be physiologically constrained from overwintering at high elevation, where resources are more limited. Previous studies documenting seasonal carry-over effects have primarily focused on consequences of winter habitat quality for subsequent migratory and reproductive performance (e.g., Marra et al. 1998; Gill et al. 2001; Norris et al. 2004). However, our results suggest that costs of reproduction during the summer could also carry over to impact migratory decisions in the fall and winter (also see Heckscher et al. 2017).

Our study adds to a growing body of evidence that individual migratory decisions are condition-dependent and reflect a balance between competing for quality breeding territories and maximizing survival prospects during seasons of resource limitation (Gillis et al. 2008; Boyle et al. 2011). Our results emphasize that migratory decisions are often more flexible than suggested by studies of obligate migrants. By studying systems in which migratory behavior is plastic, we can gain needed insights into the intrinsic and extrinsic factors that mediate those decisions and, hence, gain insight into the evolution of migratory behavior generally. Future studies like ours that follow marked individuals year-round, examine effects that carry-over across different stages of the annual cycle, test explicit predictions of mechanistic hypotheses, and tie migratory decisions to measures of individual fitness will help advance our understanding of the proximate and ultimate drivers of migration.

Acknowledgments A. Boyle and R. Duckworth provided invaluable feedback and support throughout the development and implementation of this study. R. Norris and three anonymous reviewers provided suggestions that improved the manuscript. Any use of trade, firm, or product names is for descriptive purposes only and does not imply endorsement by the U.S. Government.

Funding information CGL was supported by National Science Foundation Graduate Research Fellowship No. DGE-1143953. Arizona Field Ornithologists, T\&E Inc., and Western Bird Banding Association provided funding.

\section{Compliance with ethical standards}

Conflict of interest The authors declare that they have no conflict of interest.

Ethical approval All applicable international, national, and institutional guidelines for the use and care of animals were followed. This study was performed under a protocol approved by the University of Arizona Institutional Animal Care and Use Committee (protocol no.11-272).

\section{References}

Adriaensen F, Dhondt AA (1990) Population dynamics and partial migration of the European Robin (Erithacus rubecula) in different habitats. J Anim Ecol 59:1077-1090

Balph MH, Balph DF, Romesburg HC (1979) Social status signaling in winter flocking birds: an examination of a current hypothesis. Auk 96:79-83

Barçante L, Vale MM, Alves MAS (2017) Altitudinal migration by birds: a review of the literature and a comprehensive list of species. J Field Ornithol 88:321-335

Barton (2017) MuMIn: Multi-model Inference. R package version 1.43.6. https://CRAN.R-project.org/package=MuMIn

Bearhop S, Hilton GM, Votier SC, Waldron S (2004) Stable isotope ratios indicate that body condition in migrating passerines is influenced by winter habitat. Proc R Soc Lond B 271:S215-S218

Belthoff JR, Gauthreaux SA Jr (1991a) Aggression and dominance in house finches. Condor 93:1010-1013

Belthoff JR, Gauthreaux SA Jr (1991b) Partial migration and differential winter distribution of house finches in the eastern United States. Condor 93:374-382

Berthold P (1996) Control of bird migration. Chapman and Hall, London

Berthold P (1999) A comprehensive theory for the evolution, control, and adaptability of avian migration. Ostrich 70:1-11

Berthold P (2001) Bird migration: a general survey, 2nd edn. Oxford University Press, Oxford

Biebach H (1983) Genetic determination of partial migration in the European robin (Erithacus rebecula). Auk 100:601-606

Bosman DS, Vercruijsse HJP, Stienen EWM, Vincx M, De Neve L, Lens L (2012) Effects of body size on sex-related migration vary between two closely related gull species with similar size dimorphism. Ibis 154:52-60

Boyle WA (2008) Partial migration in birds: tests of three hypotheses in a tropical lekking frugivore. J Anim Ecol 77:1122-1128

Boyle WA (2011) Short-distance partial migration of neotropical birds: a community-level test of the foraging limitation hypothesis. Oikos 120:1803-1816

Boyle WA (2017) Altitudinal bird migration in North America. Auk 134: 443-465

Boyle WA, Conway CJ (2007) Why migrate? A test of the evolutionary precursor hypothesis. Am Nat 169:344-359

Boyle WA, Norris RD, Guglielmo CG (2010) Storms drive altitudinal migration in a tropical bird. Proc R Soc Lond B 277:2511-2519

Boyle WA, Guglielmo CG, Hobson KA, Norris DR (2011) Lekking birds in a tropical forest forego sex for migration. Biol Lett 7:661-663

Burnham KP, Anderson DR (2002) Model selection and multimodel inference: a practical information-theoretic approach, 2nd edn. Springer-Verlag, New York

Calder WA (1974) Consequences of body size for avian energetics. In: Paynter RA (ed) Avian energetics. Nuttall Ornithological Club Publ., Cambridge 
Cam E, Link WA, Cooch EG, Monnat J-Y, Danchin E (2002) Individual variation in life-history traits: seeing the trees despite the forest. Am Nat 159:96-105

Catry P, Campos A, Alanda V, Cresswell W (2004) Winter segregation of migrant European robins Erithacus rebecula in relation to sex, age, and size. J Avian Biol 35:204-209

Chambon R, Dugravot S, Paillisson J, Lemesle J, Ysnel F, Gélinaud G (2018) Partial migration in inexperienced pied avocets Recurvirostra avosetta: distribution pattern and correlates. J Avian Biol 49:e01549

Chapman BB, Brönmark C, Nilsson J, Hansson L-A (2011) The ecology and evolution of partial migration. Oikos 120:1764-1775

Creighton E (2001) Mate acquisition in the European blackbird and its implications for sexual strategies. Ethol Ecol Evol 13:247-260

Cristol DC, Baker MB, Carbone C (1999) Differential migration revisited: latitudinal segregation by age and sex class. Curr Ornithol 15:33-87

Davies NB (1978) Territorial defense in the speckled wood butterfly, Pararge aegeria: the resident always wins. Anim Behav 26:138147

Dokter AM, Farnsworth A, Fink D, Ruiz-Gutierrez V, Hochachka WM, La Sorte FA, Robinson OJ, Rosenberg KV, Kelling S (2018) Seasonal abundance and survival of North America's migratory avifauna determined by weather radar. Nat Ecol Evol 2:1603-1609

Duckworth RA (2006) Behavioral correlations across breeding contexts provide a mechanism for a cost of aggression. Behav Ecol 17:10111019

Fleischer RC, Johnston RF (1984) The relationship between winter climate and selection on body size of house sparrows. Can J Zool 62: 405-410

Fontaine JJ, Martel M, Markland HM, Niklison AM, Decker KL, Martin TE (2007) Testing ecological and behavioral correlates of nest predation. Oikos 116:1887-1894

Fretwell SD (1969) Dominance behavior and winter habitat distribution in juncos (Junco hyemalis). Bird Band 40:1-83

Fretwell SD (1972) Populations in a seasonal environment. Princeton University Press, Princeton

Fudickar AM, Schmidt A, Hau M, Quetting M, Partecke J (2013) Female-biased obligate strategies in a partially migratory population. J Anim Ecol 82:863-871

Gauthreaux SA Jr (1982) The ecology and evolution of avian migration systems. In: Farner DS, King JR (eds) Avian biology 6. Academic Press, New York, pp 93-167

Gill JA, Norris K, Potts PM, Gunnarsson TG, Atkinson PW, Sutherland WJ (2001) The buffer effect and large-scale population regulation in migratory birds. Nature 412:436-438

Gillis EA, Green DJ, Middleton HA, Morrissey CA (2008) Life history correlates of alternative migratory strategies in American dippers. Ecology 89:1687-1695

Gow EA, Wiebe KL (2014) Males migrate farther than females in a differential migrant: an examination of the fasting endurance hypothesis. R Soc Open Sci 1:1-8

Greenberg R, Marra PP (2005) Birds of two worlds: the ecology and evolution of migration. John Hopkins University Press, Baltimore

Grist H, Daunt F, Wanless S, Nelson EJ, Harris MP, Newell MA, Burthe SJ, Reid JM (2014) Site fidelity and individual variation in winter location in partially migratory European shags. PLoS One 9:e98562

Grist H, Daunt F, Wanless S, Burthe SJ, Newell MA, Harris MP, Reid JM (2017) Reproductive performance of resident and migrant males, females, and pairs in a partially migratory bird. J Anim Ecol 86: 1010-1021

Guillemain M, Hearn R, King R, Gauthier-Clerc M, Simon G, Caizergues A (2009) Differential migration of the sexes cannot be explained by the body size hypothesis in teal. J Ornithol 150:685-689

Heckscher CM, Ramirez MG, Kneidel AH (2017) Reproductive outcomes determine the timing of arrival and settlement of a single- brooded Nearctic-Neotropical songbird (Catharus fuscescens) in South America. Auk 134:842-856

Hegemann A, Marra PP, Tieleman NI (2015) Causes and consequences of partial migration in a passerine bird. Am Nat 186:531-546

Hegemann A, Fudickar AM, Nilsson JA (2019) A physiological perspective on the ecology and evolution of partial migration. J Ornithol 160:893-905

Higginson AD, McNamara JD, Houston AI (2012) The starvationpredation trade-off predicts trends in body size, muscularity, and adiposity between and within taxa. Am Nat 179:338-350

Horvath EG, Sullivan KA (1988) Facultative migration in yellow-eyed juncos. Condor 90:482-484

Jahn AE, Levey DJ, Hostetler JA, Mamani AM (2010) Determinants of partial bird migration in the Amazon Basin. J Anim Ecol 79:983992

Järvi T, Røskaft E, Bakken M, Zumsteg B (1987) Evolution of variation in male secondary characteristics: a test of eight hypotheses applied to pied flycatchers. Behav Ecol Sociobiol 20:161-169

Kaiser L (1983) Unbiased estimation in line-intercept sampling. Biometrics 39:965-976

Kendeigh SC (1945) Resistance to hunger in birds. J Wildlife Manage 9 (3): 217

Ketterson ED (1979) Status signaling in dark-eyed juncos. Auk 96:94-99

Ketterson ED, Nolan V Jr (1976) Geographic variation and its climatic correlates in the sex ratio of eastern-wintering dark-eyed juncos (Junco hyemalis hyemalis). Ecology 57:679-693

Ketterson ED, Nolan V Jr (1983) The evolution of differential bird migration. Curr Ornithol 1:357-402

Kirkpatrick C, Conway CJ (2010) Nest predators of ground-nesting birds in montane forests of the Santa Catalina Mountains, Arizona. Wilson J Ornithol 122:614-617

Klaassen RHG, Hake M, Strandberg R, Koks BJ, Trierweiler C, Exo KM, Bairlein F, Alerstam T (2014) When and where does mortality occur in migratory birds? Direct evidence from long-term satellite tracking of raptors. J Anim Ecol 83:176-184

Kokko H (2011) Directions in modelling partial migration: how adaptation can cause a population decline and why the rules of territory acquisition matter. Oikos 120:1826-1837

Kokko H, Gunnarsson TG, Morrell LJ, Gill JA (2006) Why do female migratory birds arrive later than males? J Anim Ecol 75:1293-1303

Lack D (1943) The problem of partial migration. Brit Birds 37:122-131

Lehikoinen E (1986) Dependence of winter survival on size in the great tit Parus major. Ornis Fennica 63:10-16

Lima SL (1986) Predation risk and unpredictable feeding conditions of body mass in birds. Ecology 67:377-385

Lok T, Veldhoen L, Overdijk O, Tinbergen JM, Piersma T (2017) An agedependent fitness cost of migration? Old trans-Saharan migrating spoonbills breed later than those staying in Europe, and late breeders have lower recruitment. J Anim Ecol 86:998-1009

Lundberg P (1985) Dominance behaviour, body weight and fat variations, and partial migration in European blackbirds Turdus merula. Behav Ecol Sociobiol 17:185-189

Lundberg P (1988) The evolution of partial migration in birds. Trends Ecol Evol 3:172-175

Lundberg P, Schwabl H (1983) Structure and dominance behaviour of a partial migratory population of Blackbirds Turdus merula during the non-breeding season. Ornis Fennica Suppl 3:20-21

Lundblad CG (2014) Altitudinal migration in birds: tests of four mechanistic hypotheses in yellow-eyed juncos (Junco phaeonotus). MSc thesis, University of Arizona

Lundblad CG, Conway CJ (2020) Variation in selective regimes drives intraspecific variation in life history traits and migratory behavior along an elevational gradient. J Anim Ecol 89 (published online. https://doi.org/10.1111/1365-2656.13134

Macdonald CA, McKinnon EA, Gilchrist HG, Love OP (2016) Cold tolerance, and not earlier arrival on breeding grounds, explains 
why males winter further north in an arctic-breeding songbird. $\mathrm{J}$ Avian Biol 47:7-15

Marra PP, Hobson KA, Holmes RT (1998) Linking winter and summer events in a migratory bird using stable carbon isotopes. Science 282: 1884-1886

McDonald JE (1956) Variability of precipitation in an arid region: a survey of characteristics for Arizona. University of Arizona, Institute for Atmospheric Physics, Technical Reports on the Meterology and Climatology of Arid Regions No. 1, Tucson

Middleton HA, Morrissey CA, Green DJ (2006) Breeding territory fidelity in a partial migrant, the American dipper, Cinclus mexicanus. J Avian Biol 37:169-178

Moore NJ (1972) Ethology of the Mexican Junco (Junco phaeonotus palliatus). Dissertation. University of Arizona

Morton ML (1984) Sex and age ratios in wintering white-crowned sparrows. Condor 86:85-87

National Weather Service (2017a) Monthly rainfall normals (1981-2010) across southeast Arizona, https://www.wrh.noaa.gov/twc/climate/ seaz_rainfall_normals.php. Accessed 10 Oct 2017

National Weather Service (2017b) Monthly climate report for Tucson, https://www.wrh.noaa.gov/twc/ climate/monthly.php

Nebel S (2006) Latitudinal clines in sex ratio, bill, and wing length in least sandpipers. J Field Ornithol 77:39-45

Newton I (2008) The migration ecology of birds. Elsevier, Oxford

Newton I (2012) Obligate and facultative migration in birds: ecological aspects. J Ornithol 153:S171-S180

Nolan V Jr (1978) The ecology and behavior of the prairie warbler, Dendroica discolor. Ornithol Monogr 26:1-595

Norberg R (1981) Temporary weight decrease in breeding birds may result in more fledged young. Am Nat 118:838-850

Norbu N, Wikelski MC, Wilcove DS, Partecke J, Tenzin U, Tempa T (2013) Partial migration of Himalayan forest pheasant. PLoS One 8: e60979

Norris DR, Marra PP, Kyser TK, Sherry TW, Ratcliffe L (2004) Tropical winter habitat limits reproductive success on the temperate breeding grounds in a migratory bird. Proc R Soc Lond B 271:59-64

Ogonowski MS, Conway CJ (2009) Migratory decisions in birds: extent of genetic versus environmental control. Oecologia 161:199-207

Pachauri RK, Allen MR, Barros VR et al (2014) Climate change 2014: synthesis report. Contribution of working groups I, II and III to the fifth assessment report of the Intergovernmental Panel on Climate Change. IPCC, Geneva

Palacín C, Alonso JC, Alonso JA, Magaña M, Martin CA (2011) Cultural transmission and flexibility of partial migration patterns in a longlive bird, the great bustard Otis tarda. J Avian Biol 42:301-308

Perez C, Granadeiro JP, Dias MP, Alonso H, Catry P (2014) When males are more inclined to stay at home: insights into the partial migration of a pelagic seabird provided by geolocators and isotopes. Behav Ecol 25:313-319

Perrins CM, Harris MP, Britton CK (1973) Survival of manx shearwaters Puffinus puffinus. Ibis 115:535-548

Phillips AR, Marshall J, Monson G (1964) Birds of Arizona. University of Arizona Press, Tucson

Pratt AC, Smith KT, Beck JL (2017) Environmental cues used by greater sage-grouse to initiate altitudinal migration. Auk 134:628-643

Prescott DRC (1990) Age and sex differences in winter distribution of American goldfinches in eastern North America. Ornis Scand 21: 99-104
Prescott DRC (1994) Intraspecific and geographical trends in body size of a differential migrant, the evening grosbeak. Auk 111:693-702

R Core Team (2017) R: a language and environment for statistical computing. R Foundation for Statistical Computing, Vienna. https:// www.R-project.org

Ralph CJ, Geupel GR, Pyle P, Martin TE, DeSante DF (1993) Handbook of field methods for monitoring landbirds. U.S. Forest Service, Pacific Southwest Research Station, Albany, CA

Rising JD, Somers KM (1989) The measurement of overall body size in birds. Auk 106:666-674

Runge MC, Marra PP (2005) Modeling seasonal interactions in the population dynamics of migratory birds. In: Greenberg RS, Marra PP (eds) Birds of two worlds: the ecology and evolution of migration. John Hopkins University Press, Baltimore

Schwabl H (1983) Expression and significance of the winter strategies in a partially migratory population of European blackbirds (Turdus merula). J Ornithol 124:101-116

Shepherd PCF, Lank DB, Smith BD, Warnock N, Kaiser GW (2001) Sex ratios of Dunlin wintering at two latitudes on the pacific coast. Condor 103:352-360

Sih A, Bell A, Johnson JC (2004) Behavioral syndromes: an ecological and evolutionary overview. Trends Ecol Evol 19:372-378

Sillett TS, Holmes RT (2002) Variation in survivorship of a migratory songbird throughout its annual cycle. J Anim Ecol 71:296-308

Sogge MK, Koronkiewicz TJ, van Riper CIII, Durst SL (2007) Willow flycatcher nonbreeding territory defense behavior in Costa Rica. Condor 109:475-480

Somveille M, Rodrigues ASL, Manica A (2015) Why do birds migrate? A macroecological perspective. Glob Ecol Biogeogr 24:664-674

Strandberg R, Klaassen RHG, Hake M, Alerstam T (2010) How hazardous is the Sahara Desert crossing for migratory birds? Indications from satellite tracking of raptors. Biol Lett 6:297-300

Terrill SB (1991) Evolutionary aspects of orientation and migration in birds. In: Berthold P (ed) Orientation in Birds. Birkhäuser Verlag, Basel, pp 180-201

Terrill SB, Able KP (1988) Bird migration terminology. Auk 105:205206

Tobias J (1997) Asymmetrical territorial contests in the European robin: the role of settlement costs. Anim Behav 54:9-21

Western Regional Climate Center (2017) Period of record monthly climate summary for Mt. Lemmon Arizona, https://wrcc.dri.edu/cgibin/cliMAIN.pl?az5732. . Accessed 10 Oct 2017

Wikelski M, Tarlow EM, Raim A, Diehl RH, Larkin RP, Visser GH (2003) Costs of migration in free-flying songbirds. Nature 423:704

Winger BM, Auteri GG, Pegan TM, Weeks BC (2018) A long winter for the red queen: rethinking the evolution of seasonal migration. Biol Rev 94:737-752

Witter MS, Cuthill IC (1993) The ecological costs of fat storage. Philos Trans R Soc B 340:73-92

Zeileis A, Hothorn T (2002) Diagnostic checking in regression relationships. R News 2:7-10 https://CRAN.R-project.org/doc/Rnews/

Zúñiga D, Gager Y, Kokko H, Fudickar AM, Schmidt A, Naef-Daenzer B, Wikelski M, Partecke J (2017) Migration confers winter survival benefits in a partially migratory songbird. eLife 6:1-12

Publisher's note Springer Nature remains neutral with regard to jurisdictional claims in published maps and institutional affiliations. 